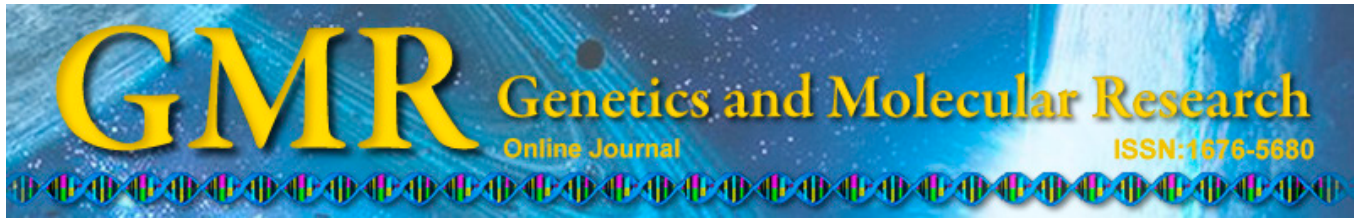

\title{
Transferability of microsatellites for studies on the social behavior of the tufted capuchin monkey (genus Sapajus)
}

\author{
M. Tokuda ${ }^{1}$, M.M. Martins² ${ }^{2}$ and P. Izar $^{3}$ \\ ${ }^{1}$ Parque Zoológico Municipal Quinzinho de Barros, Sorocaba, SP, Brasil \\ ${ }^{2}$ Universidade Santo Amaro, São Paulo, SP, Brasil \\ ${ }^{3}$ Departamento de Psicologia Experimental, Universidade de São Paulo, \\ São Paulo, SP, Brasil
}

Corresponding author: M. Tokuda

E-mail: marcostokuda@yahoo.com.br

Genet. Mol. Res. 13 (4): 9910-9914 (2014)

Received November 21, 2013

Accepted February 27, 2014

Published November 27, 2014

DOI http://dx.doi.org/10.4238/2014.November.27.19

ABSTRACT. Because of relevant results that indicated that molecular
techniques can provide increased knowledge of animal social systems,
they usually complement observational field studies. Despite the great
utility of microsatellites, they are not available for all species. Gathering
genetic information using microsatellites that were originally designed
for other species is a time-saving procedure. The aim of this study was to
test the transferability of microsatellites and their usefulness in studies
of social behavior of black capuchin monkeys (Sapajus nigritus). We
noninvasively sampled adult and subadult black capuchins of three
wild groups in southeastern Brazil. Seventeen microsatellites, which
were previously designed for and successfully amplified in multiple
Neotropical primate species, were tested. Nine of the 17 microsatellite
loci tested produced an average of 6.22 alleles (range $2-12$ ) per locus.
The allelic richness and the expected heterozygosity for all loci was 5.93
and 0.70 , respectively. The combined non-exclusion probability for one
candidate parent across all loci was 0.01 . The nine microsatellite loci 
optimized in this study have a great potential for application in studies of social structure and dispersal patterns in S. nigritus populations and in other Neotropical primate species.

Key words: Microsatellite; Capuchin monkey; Sapajus

\section{INTRODUCTION}

In the past decade, genetic analyses became an important tool in studies of animal behavior (Di Fiore, 2003) because inferences about attributes that are crucial to understanding animal social dynamics, such as kinship, dispersal, and paternity, are highly constrained by field observations only. Because of relevant results that indicated that molecular techniques can provide increased knowledge about animal sociality, they usually complement observational field studies.

Microsatellites have become feasible molecular markers in the genetic assessment of relatedness and paternity because they are highly polymorphic, selectively neutral, and follow Mendelian inheritance, thus comprising a useful tool in studies of animal behavior (Di Fiore, 2003; Selkoe and Toonen, 2006). Despite the great utility of microsatellites, they are not available for all species. In addition, their development is expensive and time-consuming. The success of transferability of microsatellites is high between congener species, but successful transfer may also be reached between genera and families (Barbará et al., 2007). The aim of this study was to test the transferability of microsatellites and their usefulness in studies of the social behavior of black capuchin monkeys (Sapajus nigritus).

Capuchin monkeys include two Neotropical primate genera, Cebus and Sapajus, that comprise 12 species (Lynch Alfaro et al., 2012). Field studies indicate that capuchin monkey social systems can be highly flexible, with intra- and interspecific variations in social organization and social structure, including sex bias in dispersal and social relationships (Jack and Fedigan, 2009; Izar et al., 2012). Most of these studies were based on behavioral observations only, and our knowledge about the behavioral flexibility of this taxon would improve with the aid of molecular techniques.

\section{MATERIAL AND METHODS}

The population studied of black capuchin monkeys lives at Carlos Botelho State Park (PECB) in São Miguel Arcanjo ( $24^{\circ} 00^{\prime}$ to $24^{\circ} 15^{\prime} \mathrm{S}, 47^{\circ} 45^{\prime}$ to $\left.48^{\circ} 10^{\prime} \mathrm{W}\right)$, State of São Paulo, southeastern Brazil. The PECB comprises an area of about $380 \mathrm{~km}^{2}$ within the Atlantic Forest domain, and with three other frontier parks, forms a continuous protected forest of more than $1200 \mathrm{~km}^{2}$. Fecal samples were collected from subadult and adult monkeys (12 females and 9 males) belonging to three different social groups (Pimenta, Testa, and Pitoco). These wild free-ranging animals were habituated to the presence of researchers, and all subadult and adult individuals were individually known. We used the commercial kit QIAamp DNA Stool Mini $\mathrm{Kit}^{\circledR}$ (Qiagen, Germany) to extract DNA. Seventeen microsatellites, which were previously designed for and successfully amplified in multiple Neotropical primate species, were tested. Four microsatellites were isolated in at least two Sapajus species (PEPC3, PEPC8, PEPC40, and PEPC59: Escobar-Páramo, 2000), one in Lagothrix lagotricha (PEPL4: Escobar-Páramo, 2000), eight in Cebus capucinus (Ceb3, Ceb8, Ceb9, Ceb11, Ceb119, Ceb120, Ceb121, and 
Ceb130: Muniz and Vigilant, 2008), one in Leontopithecus rosalia (Lr.P2BH6: Grativol et al., 2001), two in Leontopithecus chrysopygus (Leon15c85 and Leon21c75: Perez-Sweeney et al., 2005), and one in Leontopithecus chrysomelas (Lch 07 : Galbusera and Gillemot, 2008).

We labeled the forward primer of each locus with an M13 tail (Schuelke, 2000) and added a fluorescently labeled universal M13 primer to the polymerase chain reaction (PCR) after the final extension step, as suggested by de Arruda et al. (2010). Our 10- $\mu$ L reaction volume contained $2 \mu \mathrm{L}$ DNA, $5 \mu \mathrm{L}$ GoTaq Colorless Master Mix (Promega, USA), $1 \mu \mathrm{L}$ bovine serum albumin (Fermentas, Lithuania), $1 \mu \mathrm{L}$ forward primer, and $1 \mu \mathrm{L}$ reverse primer. Amplifications were carried out under the following conditions: an initial denaturation step at $95^{\circ} \mathrm{C}$ for $3 \mathrm{~min} ; 45$ cycles at $95^{\circ} \mathrm{C}$ for $30 \mathrm{~s}$, annealing at $48-60^{\circ} \mathrm{C}$ for $30 \mathrm{~s}$, and extension at $72^{\circ} \mathrm{C}$ for $30 \mathrm{~s}$; and a final extension for $10-15 \mathrm{~min}$ at $72^{\circ} \mathrm{C}$. Then, 10 cycles at $94^{\circ} \mathrm{C}$ for $30 \mathrm{~s}, 53^{\circ} \mathrm{C}$ for $45 \mathrm{~s}$, and $72^{\circ} \mathrm{C}$ for $45 \mathrm{~s}$. Amplified fragments were checked on $2 \%$ agarose gels. PCR products were analyzed on a MegaBACE (GE Healthcare, USA) automatic sequencer, and allele sizes were scored using the FRAGMENT PROFILER program version 1.2 (Applied Biosystems ${ }^{\circledR}$, USA). We used the GENEPOP version 4.0 (Raymond and Rousset, 1995) to test for departures from Hardy-Weinberg equilibrium (HWE) and linkage disequilibrium (LD). We addressed the overall genetic diversity and the exclusion probability of the first parent $\left(\mathrm{Pe}_{1}\right)$ using the CERVUS version 3.0 (Kalinowski et al., 2007) and FSTAT version 2.9.3 software (Goudet, 2001). We checked for the presence of null alleles with the MICRO-CHECKER version 2.2.3 (Van Oosterhout et al., 2004).

\section{RESULTS}

Ten of the 17 microsatellites (59\%) were successfully transferred. We managed to find alleles in four homologous loci at the genus level and in six heterologous loci. The PEPC8 locus was excluded from the analysis because only three individuals (14\%) were successfully genotyped. The loci Leon15c85, Lr.P2BH6, Ceb08, Ceb09, Ceb119, Ceb120, and Ceb121 did not amplify.

The number of alleles per locus produced by the 9 microsatellites ranged from 2 to 12 , with a mean of 6.22 (Table 1). The average allelic richness was 5.93, the expected heterozygosity was 0.70 , and Pe 1 across all loci was 0.01 (Table 1). The loci Leon21c75 and Lch $\mu 07$

\begin{tabular}{|c|c|c|c|c|c|c|c|c|c|}
\hline Locus & GenBank accession & $\mathrm{Ta}\left({ }^{\circ} \mathrm{C}\right)$ & $\mathrm{N}$ & $N_{\mathrm{A}}$ & $\mathrm{R}_{\mathrm{S}}$ & $\mathrm{Pe}_{1}$ & $H_{\mathrm{O}}$ & $H_{\mathrm{E}}$ & $\overline{P_{H W E}}$ \\
\hline $\mathrm{PEPC}^{\mathrm{a}}$ & AF103994 & 51 & 18 & 12 & 11.06 & 0.36 & 0.89 & 0.92 & 0.07 \\
\hline PEPC40 & AF103997 & 54 & 19 & 4 & 4.00 & 0.69 & 0.63 & 0.75 & 0.02 \\
\hline PEPC59a & AF103998 & 48 & 21 & 5 & 4.67 & 0.69 & 0.48 & 0.74 & 0.04 \\
\hline PEPL4 $^{\mathrm{a}}$ & AF104000 & 51 & 16 & 10 & 9.83 & 0.48 & 0.69 & 0.90 & 0.03 \\
\hline $\mathrm{Ceb}^{\mathrm{b}}$ & EU019198 & 54 & 21 & 2 & 2.00 & 0.88 & 0.33 & 0.51 & 0.18 \\
\hline Ceb11 ${ }^{\text {b }}$ & EU019204 & 55 & 21 & 2 & 1.89 & 0.41 & 0.10 & 0.09 & 1.00 \\
\hline Ceb130 & EU019215 & 60 & 20 & 8 & 7.53 & 0.54 & 0.75 & 0.83 & 0.02 \\
\hline Leon $21 \mathrm{c} 75^{\mathrm{c}}$ & AY706922 & 52 & 18 & 5 & 4.73 & 0.99 & 0.44 & 0.68 & $0.00 *$ \\
\hline $\operatorname{Lch} \mu 07^{\mathrm{d}}$ & DQ979350 & 53 & 14 & 8 & 8.00 & 0.76 & 0.86 & 0.88 & $0.00 *$ \\
\hline All loci & & & & 6.22 & 5.93 & 0.01 & 0.57 & 0.70 & \\
\hline
\end{tabular}

$\mathrm{Ta}=$ annealing temperature; $\mathrm{N}=$ number of genotyped individuals; $N_{\mathrm{A}}=$ number of alleles; $\mathrm{R}_{\mathrm{S}}=$ allelic richness; $\mathrm{Pe}_{1}=$ non-exclusion probability for one candidate parent; $H_{\mathrm{O}}=$ observed heterozygosity; $H_{\mathrm{E}}=$ expected heterozygosity; $\mathrm{P}_{\mathrm{HWE}}=$ Hardy-Weinberg equilibrium test. *Departs significantly from HWE at $\mathrm{P}=0.017$ after correction (Benjamini and Yekutieli, 2001). ${ }^{a}$ Escobar-Páramo (2000); ${ }^{b}$ Muniz and Vigilant (2008); ${ }^{\circ}$ Perez-Sweeney et al. (2005); ${ }^{\mathrm{d}}$ Galbusera and Gillemot (2008). 
showed significant deviations from HWE, but the deviations were not associated with the occurrence of null alleles. In the pooled analysis, we recorded a significant $(\mathrm{P}=0.00)$ departure from HWE. No loci pair exhibited significant LD [P > 0.017 after Benjamini and Yekutieli correction (Benjamini and Yekutieli, 2001)]. The inbreeding coefficient for all loci was 0.18 (P large $=0.01,180$ randomizations), indicating no sign of inbreeding. Null alleles were detected at the loci PEPC59 and PEPL4.

\section{DISCUSSION}

The allelic richness and heterozygosity values suggest considerable genetic diversity in the PECB population of $S$. nigritus. The deviations from HWE recorded for the Leon21c75 and Lch $\mu 07$ loci may have resulted from a deficit of heterozygotes and, in the pooled analysis, from the presence of null alleles in the two loci. Allele dropout may also lead to HWE deviations. However, in order to minimize this type of error, we genotyped at least $85 \%$ of the homozygous samples three times. In addition, we genotyped at least $70 \%$ of the heterozygous samples twice. The low value for $\mathrm{Pe}_{1}$ may constrain the reliable identification of fathers in paternity analysis if only candidates from the three studied groups are considered. However, increasing the sample size may offset this.

Because the selection of appropriate microsatellite loci is a crucial step to genetic analyses and because field studies on primate social behavior require extensive data collection, we believe that our efforts are useful for field primatologists interested in applying genetic analyses in studies of social behavior. Many questions about features of primate social systems were only properly answered when genetic analyses were incorporated with field observations, for example, the complex sex-biased dispersal pattern in Colobus guereza (Harris et al., 2009) and inbreeding avoidance in Cebus capucinus (Muniz et al., 2006). Our results highlight the success of transferability among close and more distantly related species. A higher rate of transferability within and between genera is expected among mammals compared to other vertebrate groups (Barbará et al., 2007). In conclusion, the nine microsatellite loci optimized in this study have a great potential for application in studies of social structure and dispersal patterns of $S$. nigritus populations and in other Neotropical primate species.

\section{ACKNOWLEDGMENTS}

We thank the Instituto Florestal de São Paulo and José Carlos Maia for permission to conduct the research at PECB. We thank especially Prof. Dr. Pedro Manoel Galetti Junior for permission to use the Laboratório de Biodiversidade Molecular e Conservação, and we also thank Eraldo Vieira for assistance in the field. Research supported by Coordenação de Aperfeiçoamento de Pessoal de Nível Superior (CAPES) and Fundação de Amparo à Pesquisa do Estado de São Paulo (FAPESP) (\#09/50182-2 and \#09/51589-9).

\section{REFERENCES}

Barbará T, Palma-Silva C, Paggi GM, Bered F, et al. (2007). Cross-species transfer of nuclear microsatellite markers: potential and limitations. Mol. Ecol. 16: 3759-3767.

Benjamini Y and Yekutieli D (2001). The control of the false discovery rate in multiple testing under dependency. Ann. Stat. 29: 1165-1188.

de Arruda MP, Goncalves EC, Schneider MP, da Silva AL, et al. (2010). An alternative genotyping method using dye- 
labeled universal primer to reduce unspecific amplifications. Mol. Biol. Rep. 37: 2031-2036.

Di Fiore A (2003). Molecular genetic approaches to the study of primate behavior, social organization, and reproduction. Am. J. Phys. Anthropol. (Suppl 37): 62-99.

Escobar-Páramo P (2000). Microsatellite primers for the wild brown capuchin monkey Cebus apella. Mol. Ecol. 9: 107108.

Galbusera PHA and Gillemot S (2008). Polymorphic microsatellite markers for the endangered golden-headed lion tamarin, Leontopithecus chrysomelas (Callitrichidae). Conserv. Genet. 9: 731-733.

Goudet J (2001). FSTAT, A Program to Estimate and Test Gene Diversities and Fixation Indices (Version 2.9.3). Available at [http://www2.unil.ch/popgen/softwares/fstat.htm].

Grativol AD, Ballou JD and Fleischer RC (2001). Microsatellite variation within and among recently fragmented populations of the golden lion tamarin (Leontopithecus rosalia). Conserv. Genet. 2: 1-9.

Harris TR, Caillaud D, Chapman CA and Vigilant L (2009). Neither genetic nor observational data alone are sufficient for understanding sex-biased dispersal in a social-group-living species. Mol. Ecol. 18: 1777-1790.

Izar P, Verderane MP, Peternelli-Dos-Santos L, Mendonca-Furtado O, et al. (2012). Flexible and conservative features of social systems in tufted capuchin monkeys: comparing the socioecology of Sapajus libidinosus and Sapajus nigritus. Am. J. Primatol. 74: 315-331.

Jack KM and Fedigan LM (2009). Female dispersal in a female-philopatric species, Cebus capucinus. Behaviour 146: 471-497.

Kalinowski ST, Taper ML and Marshall TC (2007). Revising how the computer program CERVUS accommodates genotyping error increases success in paternity assignment. Mol. Ecol. 16: 1099-1106.

Lynch Alfaro JW, Boubli JP, Olson LE and Di Fiore A (2012). Explosive Pleistocene range expansion leads to widespread Amazonian sympatry between robust and gracile capuchin monkeys. J. Biogeogr. 39: 272-288.

Muniz L and Vigilant L (2008). Isolation and characterization of microsatellite markers in the white-faced capuchin monkey (Cebus capucinus) and cross-species amplification in other New World monkeys. Mol. Ecol. Resour. 8: 402-405.

Muniz L, Perry S, Manson JH, Gilkenson H, et al. (2006). Father-daughter inbreeding avoidance in a wild primate population. Curr. Biol. 16: R156-R157.

Perez-Sweeney B, Valladares-Padua C, Burrell AS and Di Fiore A (2005). Dinucleotide microsatellite primers designed for a critically endangered primate, the black lion tamarin (Leontopithecus chrysopygus). Mol. Ecol. Notes 5: 198201.

Raymond M and Rousset F (1995). Genepop v. 1.2: population genetics software for exact tests and ecumenicism. $J$. Hered. 86: 248-249.

Schuelke M (2000). An economic method for the fluorescent labeling of PCR fragments. Nat. Biotechnol. 18: 233-234.

Selkoe KA and Toonen RJ (2006). Microsatellites for ecologists: a practical guide to using and evaluating microsatellite markers. Ecol. Lett. 9: 615-629.

Van Oosterhout C, Hutchinson WF, Wills DPM and Shipley P (2004). Micro-Checker: software for identifying and correcting genotyping errors in microsatellite data. Mol. Ecol. Notes 4: 535-538. 